\title{
The ups and downs of ecstasy
}

\author{
The clubbers' drug is now being studied as a treatment for anxiety and \\ post-traumatic stress disorder. Erika Check charts its rocky road from \\ the psychedelic underground to the psychiatric clinic.
}

O n 16 April, a patient suffering from post-traumatic stress disorder visited a psychiatrist's office in Charleston, South Carolina, to try a new experimental treatment. She is the first of 20 people who have signed up for the trial. Like the others, she suffers from flashbacks, nightmares and years of painful memories, despite receiving counselling and antidepressant drugs. Each of the volunteers will undergo further counselling, this time in combination with doses of 3,4-methylenedioxymethamphetamine, or MDMA - the active ingredient in the recreational drug ecstasy.

The study is a landmark victory for a group that has fought long and hard to bring drugs such as MDMA into the clinic. The Multidisciplinary Association for Psychedelic Studies (MAPS), based in Sarasota, Florida, has been arguing since the mid1980s that MDMA is a powerful therapeutic tool. Its leader, Rick Doblin, now hopes that a similar study in Spain will be allowed to resume after a two-year hiatus. He is also working with doctors in Israel to plan trials there. And MAPS has donated money to Harvard Medical School in Boston, where psychiatrist John Halpern is planning a trial to test whether MDMA can relieve anxiety and pain in end-stage cancer patients.

MDMA is classified as a hallucinogen, and other members of this class of drugs are also attracting renewed interest as treatments for psychiatric conditions (see 'Can mushrooms work their magic?', overleaf). The primary effect of these drugs is to alter perception, cognition or mood ${ }^{1}$. People who take ecstasy recreationally generally experience a feeling of euphoria. And in the 1980s, a few patients started taking the drug as an aid to psychotherapy. There were no rigorous clinical trials, but some users said that the drug helped them to trust others and to understand themselves better ${ }^{2}$.

There are obvious parallels with the underground culture that surrounded LSD, or lysergic acid diethylamide, in the late 1960s and early 1970s. Although many users were simply intrigued by the hallucinations induced by the drug, some claimed that LSD sent them on a self-improving voyage of psychological discovery.

Doblin was part of this psychedelic underground. He grew up in a wealthy suburb north of Chicago, and started taking LSD in 1971 as a student at the New College of Florida in Sarasota, where students develop individual programmes of study. At the time, Doblin was troubled by emotions that he attributes to the loss of some of his relatives in the Holocaust. "I had been suffering with the awareness that this scapegoating and cultural insanity was a direct threat to me," he says. "LSD just helped me put it all together." The experience also underpinned Doblin's self-directed major in 'transpersonal psychedelic psychotherapy'.

\section{Going underground}

Convinced of the healing power of psychedelic drugs, Doblin later began to train as an underground therapist, beginning by sitting in on therapy sessions aided by LSD and MDMA. But his budding career as a therapist hit a snag in 1985, when a young graduate student named George Ricaurte reported that a related hallucinogen called MDA was toxic to rat neurons that produce serotonin, a neurotransmitter chemical that carries signals between brain cells that help control mood ${ }^{3}$. The US Drug Enforcement Administration promptly outlawed both MDA and MDMA.

This decision sparked Doblin to switch course to focus on legalizing MDMA and other psychedelic drugs. In 1988, he enrolled at Harvard University's Kennedy School of Government, where he earned a doctorate by studying the US medical regulatory system.

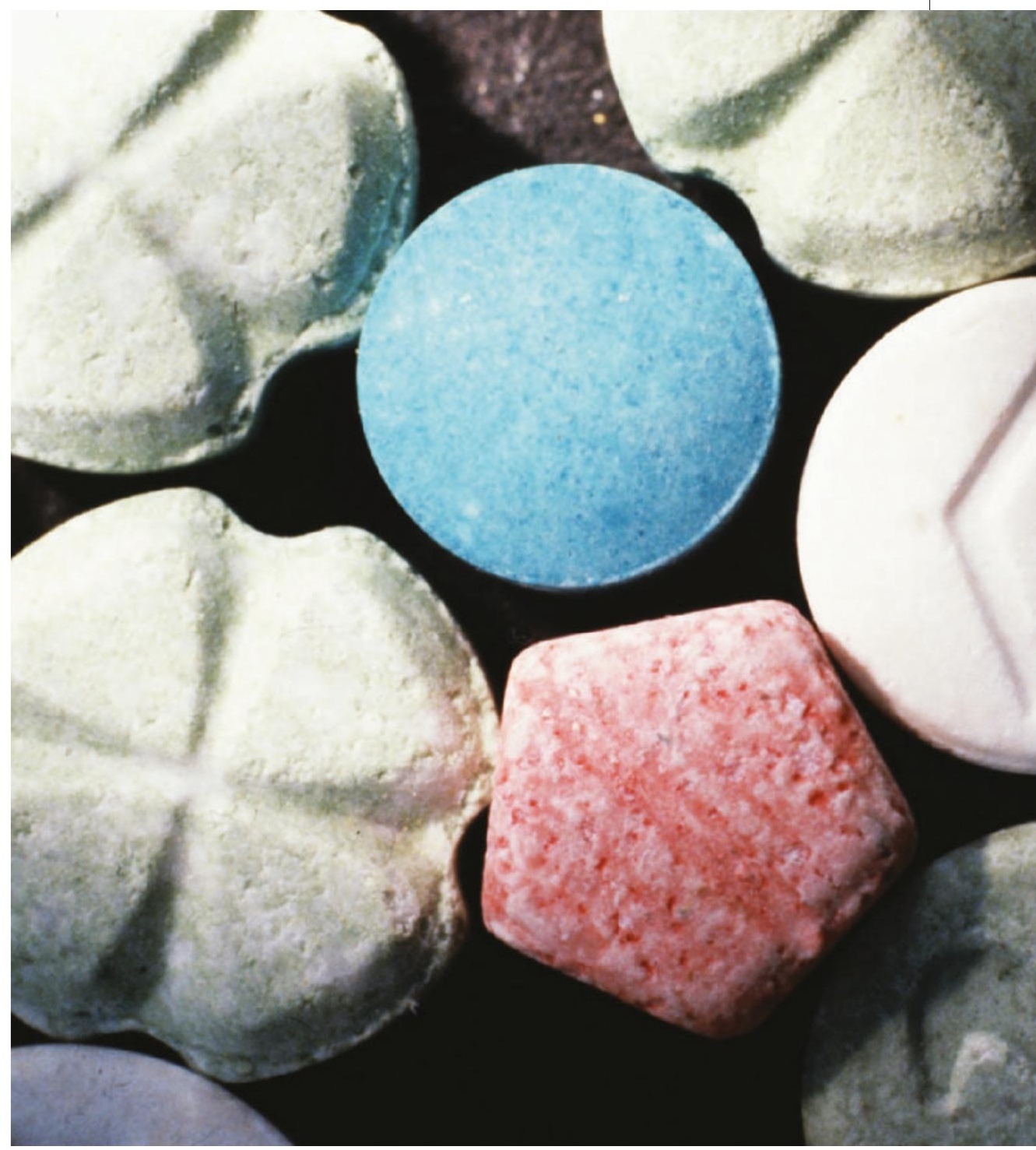


And he founded MAPS to fund research on the mental and physical effects of psychedelic drugs.

One of MAPS' earliest projects was a study in which MDMA was given to monkeys to examine its effects in the brain ${ }^{4-6}$. This project was led by Ricaurte, and the pair's fortunes have been tied together ever since. Initially, their relations were friendly - Doblin was even invited to Ricaurte's 1990 wedding to his colleague Una McCann. But more recently, they have become forthright opponents in the debate over the safety of MDMA, and whether it has a place in the psychiatric clinic.

Doblin believed that studies by Ricaurte and others would eventually demonstrate that MDMA was safe. But contrary to his hopes, this work - in particular results that have emerged from Ricaurte's lab at Johns Hopkins University in Baltimore, Maryland — has thrown up successive obstacles.

Most experts agree that MDMA decreases brain levels of serotonin in animals, and damages the branches through which serotonin-producing neurons reach out and connect to other cells ${ }^{7}$. It is difficult

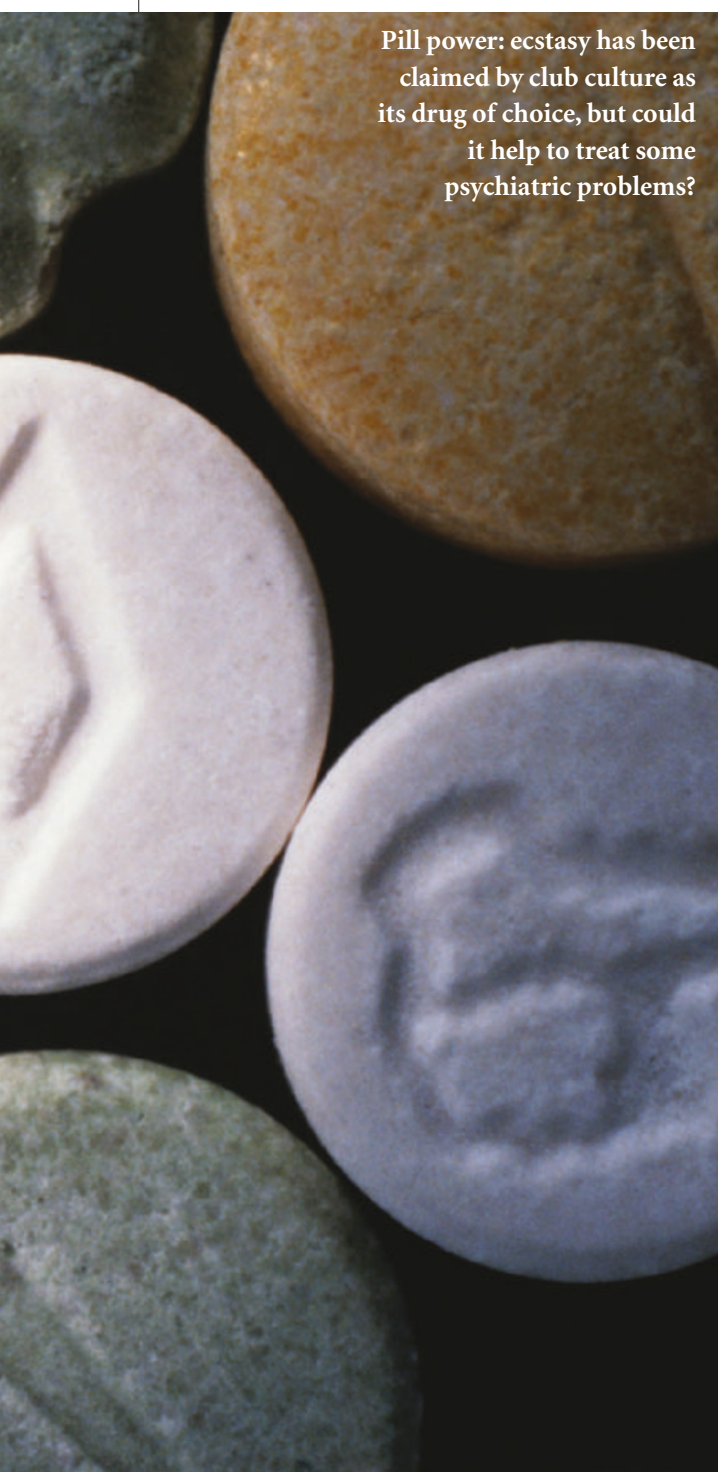

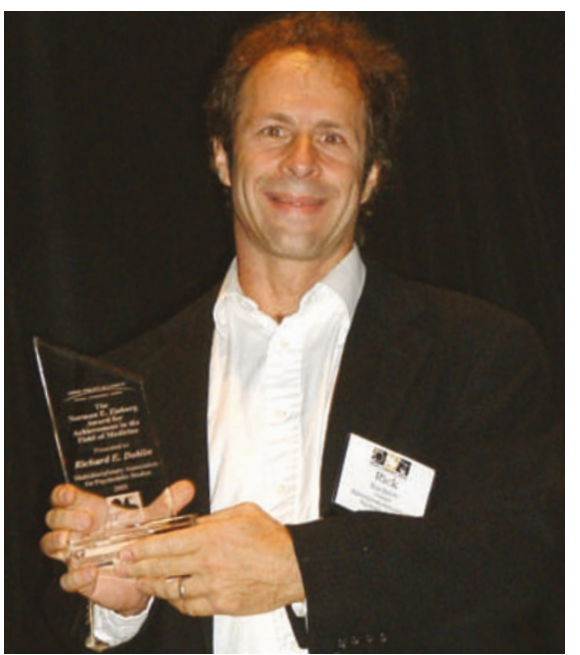

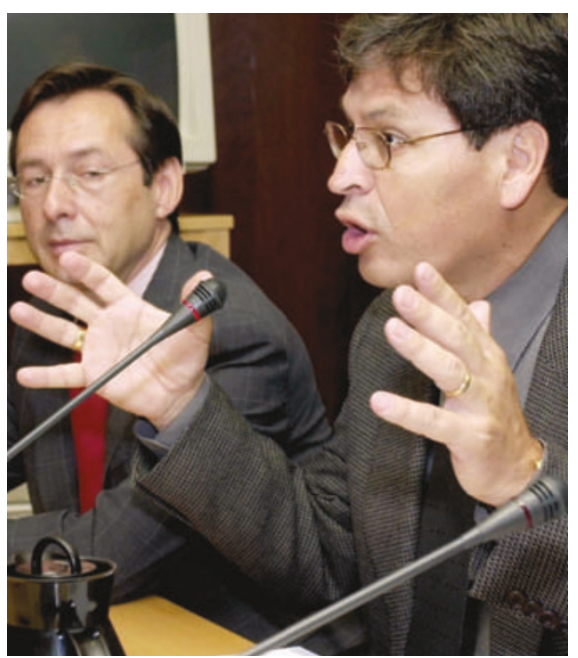

Rick Doblin (left) and George Ricaurte (far right) have clashed over the safety of MDMA.

to determine whether the same changes happen in the brains of human MDMA users. But Ricaurte's group has used various indirect methods to find evidence that suggests they do, including measurements of a breakdown product of serotonin in cerebrospinal fluid $^{8}$. Using a radioactive chemical that binds to serotonin receptors, the researchers have also shown from positron emission tomography brain scans that MDMA users have fewer receptors for the neurotransmitter". "The bottom line is that over 15 years worth of research by us and others has clearly demonstrated that MDMA is toxic to brain serotonin neurons," McCann argues.

But the debate still rages over the long-term consequences of this damage. There are hints that MDMA affects processes such as sleep cycles ${ }^{10}$, but more alarming possibilities come from studies that indicate that MDMA users have poorer memory and impaired thought processes, compared with people who haven't tried the drug $^{11,12}$. The problem with ascribing these effects to ecstasy is that people who take MDMA also frequently stay up all night dancing and may also take other drugs.

The definitive test would be to give MDMA in a controlled setting to people who have never tried it before. In 1998, Franz Vollenweider of the Psychiatric University Hospital in Zurich, Switzerland, published a study in which he did just that, reporting on the drug's immediate cognitive effects, which included "moderate thought disorder"13. It was a highly controversial study, with critics including Ricaurte and McCann ${ }^{14}$ arguing that it was unethical to give people a drug that could cause permanent brain damage. Vollenweider did not study the treatment's long-term effects.

Amid this contentious debate, MAPS nevertheless managed to get the US Food and Drug Administration in 2001 to approve a clinical trial of MDMA in patients with post-traumatic stress disorder. But in September 2002, Ricaurte, McCann and their colleagues published a paper in Science ${ }^{15}$ that seemed to spell the end for MDMA as a therapeutic tool. The researchers gave squirrel monkeys and baboons doses of the drug that they claimed were similar to those taken by some clubbers in a single night. This killed neurons that produce the neurotransmitter dopamine, and led to a condition similar to Parkinson's disease. Two out of ten of the animals died.

"We already know from the literature that brain dopamine declines with age," Ricaurte said at the time. "A young individual who sustains injury to these dopamine cells and depletes their reserve may be at greater risk of parkinsonism."

The resulting furore marked the nadir of Doblin's relationship with Ricaurte and McCann. After the paper had been submitted to Science, Doblin claims that McCann torpedoed MAPS' effort to start its clinical trial, which needed ethical clearance from an Institutional Review Board (IRB) before any patients were treated. The Western IRB, based in Olympia, Washington state, had told Doblin on 10 July 2002 that it would approve the study. But this approval was revoked on 4 September, says Doblin, after a doctor affiliated with the board spoke on the telephone with McCann.

\section{Hard to swallow}

Ricaurte's shocking findings were also bad news for Jose Carlos Bouso of the Autonomous University of Madrid in Spain. In late 2001, Bouso had earned regulatory approval and begun his own study of MDMA as a treatment for patients with post-traumatic stress disorder. Political pressure led Spanish drug-enforcement officials to halt the trial in May 2002, but Bouso was pressing to get it restarted. After 


\section{Can mushrooms work their magic?}

While the controversy surrounding ecstasy has been grabbing the headlines, a quiet revolution in psychedelic-drug research has been under way. Over the past year, doctors have begun a handful of trials to test natural hallucinogenic drugs in psychiatric medicine.

Proponents of such trials say that Native American cultures have used such drugs for hundreds of years, and that doctors can build on this knowledge to learn how to use them. Psychiatrist John Halpern of Harvard Medical School in Boston has been studying the use of the hallucinogenic peyote cactus by the Native American Church, which holds that it is a religious sacrament handed down from God. The cactus contains the drug mescaline, and is taken during religious rituals to cure drug addiction and alcoholism. So far, says Halpern, preliminary observational studies have not shown the drug to have major side effects.

Meanwhile, Francisco Moreno of the University of Arizona at Tucson has treated eight patients with psilocybin, the active ingredient in 'magic' mushrooms (above right). $\mathrm{He}$ is testing anecdotal reports that the drug can help patients to manage symptoms of obsessive-compulsive disorder. And psychiatrist Charles Grob at the University of California, Los Angeles, is also testing psilocybin to relieve anxiety in terminally ill cancer patients.

Regulators have given these studies an easier time than those involving ecstasy

publication of the Science paper, Doblin claims that Ricaurte impeded these efforts by making public speeches in Spain about the hazards of MDMA.

Ricaurte declined to be interviewed for this article, responding by e-mail: "I would think that it is preferable for a journal like Nature to focus on scientific issues related to MDMA, rather than personalities." But McCann argues that Doblin's complaints about her interaction with the Western IRB are based on a misunderstanding. She says that she did not discuss the results from the Science paper, and initially gave the trial her tentative backing, believing that it would be conducted in a hospital. But when she later learned that it would be run in a psychiatrist's office, she expressed misgivings. "I'd rather it be done in a hospital setting," McCann says. When the Western IRB withheld its approval, the trial's location was cited as one reason for the decision.

Doblin's crusade to bring MDMA into the clinic seemed to have finally been defeated. But in an embarrassing climbdown, Ricaurte and his colleagues were forced to retract their paper in September 2003, after discovering that the monkeys had actually been injected with methamphetamine, rather than MDMA (ref. 16). The

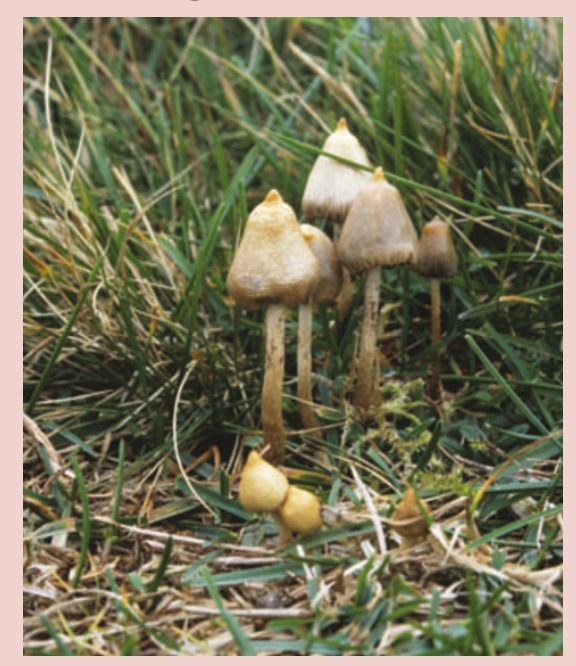

because mescaline and psilocybin don't seem to damage the brain, and also don't put people who take them under cardiovascular stress.

But even the proponents of such studies caution that the drugs are not risk-free. Moreno, for instance, says that psilocybin is safe when used under supervision in a controlled environment, but can cause intense and frightening hallucinations if people are not prepared for the experience. "If people aren't in the right mindset, hallucinations can be very threatening," he says. In his trial, Moreno is testing a range of doses to find out whether patients even need to experience psilocybin's full hallucinogenic effect to derive benefit from the drug.

researchers blamed mislabelling by their suppliers at the National Institute on Drug Abuse in Bethesda, Maryland.

Just 18 days later, an IRB based in North Carolina stamped the MAPS study with its seal of approval. And on 24 February this year, the trial cleared its final hurdle when the Drug Enforcement Administration granted psychiatrist Michael Mithoefer a licence to dispense MDMA.

Each of the 20 patients in the trial will be given 11 hours of psychotherapy without any drugs. They will also undergo two different eight-hour sessions about a month apart, after which they will spend the night at Mithoefer's private clinic in Charleston. During these sessions, 12 patients will take MDMA, whereas eight will take a placebo.

\section{A question of trust}

Mithoefer, who also has an academic appointment at the Medical University of South Carolina, hopes that MDMA will help these patients to overcome their fears and trust him as their therapist. "They have trouble forming therapeutic relation- ships," he explains. "Our hypothesis is that it may allow people to overcome those obstacles." But with so few patients enrolled in the study, this first trial won't produce a definitive answer. "This is a pilot study to see if there's any suggestion that MDMA can be useful," says Mithoefer. His first goal is to find out whether the drug is safe for people who have never taken MDMA before.

Apart from the question of whether the drug damages the brain, there are concerns about its cardiovascular effects. For instance, in 1996, Charles Grob, a psychiatrist at the University of California, Los Angeles, published a safety trial on 19 people, two of whom developed high blood pressure ${ }^{17}$. Grob had been considering giving MDMA to patients with end-stage cancer, to test whether it would help them to confront their anxiety about dying. But the political flap over ecstasy and the cardiovascular stress he observed has since made him turn instead to another psychedelic drug, psilocybin.

Doblin still has a lot of work to do if MDMA is ever to be embraced by the medical mainstream. But he sees the South Carolina trial as a key victory, and hopes that doctors and regulators will eventually change their minds if research proves that MDMA and other psychedelic drugs are safe and clinically effective. "We are at the forefront of studying risk and benefit," Doblin says. "We hope that there's enough respect for science that people will judge us on the basis of our data."

Erika Check is Nature's Washington biomedical

\section{correspondent.}

1. Abraham, H. D., Aldridge, A. M. \& Gogia, P.

Neuropsychopharmacology 14, 285-298 (1996).

2. Greer, G. \& Tolbert, R. J. Psychoactive Drugs 18, 319-327 (1986)

3. Ricaurte, G., Bryan, G., Strauss, L., Seiden, L. \& Schuster, C. Science 229, 986-988 (1985).

4. Ricaurte, G. A., DeLanney, L. E., Irwin, I. \& Langston, J. W. Brain Res. 446, 165-168 (1988).

5. Ricaurte, G. A. et al. J. Am. Med. Assoc. 260, 51-55 (1988) 6. Ricaurte, G. A., DeLanney, L. E., Wiener, S. G., Irwin, I. \& Langston, J. W. Brain Res. 474, 359-363 (1988). Green, A. R., Mechan, A. O., Elliott, J. M., O'Shea, E. \& Colado, M. I. Pharmacol. Rev. 55, 463-508 (2003).

8. McCann, U. D., Ridenour, A., Shaham, Y. \& Ricaurte, G. A. Neuropsychopharmacology 10, 129-138 (1994)

9. McCann, U. D., Szabo, Z., Scheffel, U.

Dannals, R. F. \& Ricaurte, G. A. Lancet 352, 1433-1437 (1998).

10. Allen, R. P., McCann, U. D. \& Ricaurte, G. A. Sleep 16, 560-564 (1993).

11. Montoya, A. G., Sorrentino, R., Lukas, S. E. \& Price, B. H. Harv. Rev. Psychiatry 10, 212-220 (2002).

12. Morgan, M. J. Psychopharmacology 152, 230-248 (2000). 13. Vollenweider, F. X., Gamma, A., Liechti, M. \& Huber, T. Neuropsychopharmacology 19, 241-251 (1998).

14. McCann, U. D. \& Ricaurte, G. A. Neuropsychopharmacology 24, 333-336 (2001)

15. Ricaurte, G. A., Yuan, J., Hatzidimitriou, G., Cord, B. J. \& McCann, U. D. Science 297, 2260-2263 (2002).

16. Ricaurte, G. A., Yuan, J., Hatzidimitriou, G., Cord, B. J. \& McCann, U. D. Science 301, 1479 (2003).

17. Grob, C. S., Poland, R. E., Chang, L. \& Ernst, T. Behav. Brain Res. 73, 103-107 (1996).

www.maps.org 